\title{
Unfinished business: Craft and revivification
}

\author{
Mae Finlayson and Karen Hall
}

\begin{abstract}
Reactivating incomplete and discarded domestic craft projects is an exploration of how such objects can mediate between presence and absence. Contemporary creative work that gathers and reclaims the unfinished projects acknowledges, extends and plays with their rich materiality as well as the dormant stories embedded within them. Using unfinished objects can be a way of speaking to loss and absence, and an assertion of the presence of other voices in the act of repurposing. A material dialogue, created through the trace of the hand and the repetitive labour of crafting, emphasises the potential within these discarded objects. The tension between the implied presence of the first maker and the displacement of the past through revivification is the entry point to nostalgia, a label that implies both being out of place as well as out of time. While nostalgia is often seen as an innately conservative practice, functioning as a reductive stand-in for the richness of the past, we take up Svetlana Boym's (2001) argument that the impossible longing of reflective nostalgia can be productive, humorous and utopian. This essay explores the interplay of past and present in the process of finding, remaking and repurposing.
\end{abstract}

\section{Introduction}

Unfinished craft articles retain their makers' touch - material touch upon literal material. What happens when that presence becomes absence? This absence becomes especially curious when the making has been started, and then stopped, and left incomplete. These incomplete projects tantalise with the dormant stories embedded within them - what was this object intended to be? Why has it been left unfinished? What will happen to it? While such unfinished work may be the simple detritus left behind by a developing craft practice, or sacrifices in the face of insufficient time, energy and creative space, it also offers eloquent possibilities for engagement. Taking up these discarded objects to reactivate them - to insert the presence of another maker, and to resolve the work in a way unintended at its origin - creates a dialogue between past and present, presence and absence, materiality and memory.

In this essay we discuss the implications of intervening in unfinished objects as a mode of creative practice, and consider how these interventions interact with the contexts in which the objects were started, halted and revived. The particular focus will be on domestic textile items, particularly craft projects, both produced from commercial kits or instructions and self-defined. Formatted as a dialogue between practitioner (Mae Finlayson) and theorist (Karen Hall), 
we use recent works by Finlayson to illuminate our discussion. We begin by considering the implications of unfinished projects - the ways in which they speak of absence and presence. We propose that the mediation created by intervention in the object creates a dialogue between makers. We then move on to the tangible nature of these objects: their existence as the product of often intensive and repetitive labour, which creates a trace or signature of the original nature imprinted upon the unfinished object. The repurposing of this object, therefore, requires material intervention, the touch of another set of hands forming a countersignature. The materiality of objects, and their persistence through time, also poses a challenge for their re-imagining: what meanings are constructed as these objects are found, selected and brought together into assemblages both in informal working collections and through exhibition? To what extent can we see the objects asserting some form of agency? Finally, we offer a theoretical frame for understanding this work, drawing on Svetlana Boym's (2001) model of restorative nostalgia as a way of understanding the temporality of unfinished objects that, in renewal, can both acknowledge the past while opening into the future.

\section{Monumental floss}

I met Janis at the local Sunday flea market. He told me he had recently returned home to Launceston from Spain to see his mother before she passed away. He sat amongst a huge display of handwoven rag rugs and hand embroidered wall hangings. In front of him was a trestle table covered in small mountains of doilies. Fine, delicate, hand-crocheted doilies in traditional neutral cottons and chunky, sparkly ones in pink and green and blue. Tablecloths, shawls and side runners hung from rails, all made by hand - by Janis's mother's hand/s. In the piles I found a lace fish, it was white and gold and as light as a piece of paper. Janis told me it was made to go onto the arm of a chair and its pair was still at home in the lounge - he said he would bring it to the market for me one day, but not just yet in case it upset his father. On the ground at his feet were opened suitcases and broken cardboard boxes bursting and spilling with both loose and bagged-up yarns, wools and cottons. All the leftover (or not yet got to) raw materials that had been knitted, knotted, stitched and hooked to form the crafted artefacts that surrounded Janis.

As I picked out bits and pieces he told me how he remembered coming home from school to find his mother and her friends sitting around the kitchen table drinking Greek coffee and chatting and laughing and making. He told me some of his mother's friends had come to visit him at the stall. They held up doilies, reminisced and recognised particular pieces. They remembered and retold particular stories. For them, visiting Janis's stall was something like visiting a memorial to pay their respects to a lifelong friend. For me, visiting Janis's stall was (and is) something like visiting a temporary memorial to pay my respects at a monument to vast quantities of human time - tangible time. 
In my studio, looking through the things that I had bought from Janis, I was affected by the unique beauty in the irregularly shaped hand-rolled balls of yarn. Some were huge, some were small, and they all had similar but slightly differing shaping. They were mixed in amongst machine-wound cones and balls, also beautiful, but in the exacting way that can only be produced by machines, just as the handrolled has beauty in the imperfect individual way that can only be produced by humans. I threaded a mixture of balls of neutral cottons, rayons and wools onto a string - like giant soft beads. I hung the string over a beam that carried the weight of the surprisingly heavy assemblage. The string of beads hovered just above a stacked spire of wool sitting, totem like, on the floor. The totem was nestled in a richly crocheted and scrunched-up tablecloth. When this was exhibited people said it looked like a stalactite and a stalagmite. It made me think of the way we were taught to remember which was which in school: stalactites hang and hold on tight, while stalagmites grow with all their might. There is a gap left between the hanging string of yarn beads and the wool totem. A void - a negative space where you might imagine there used to be a connection.

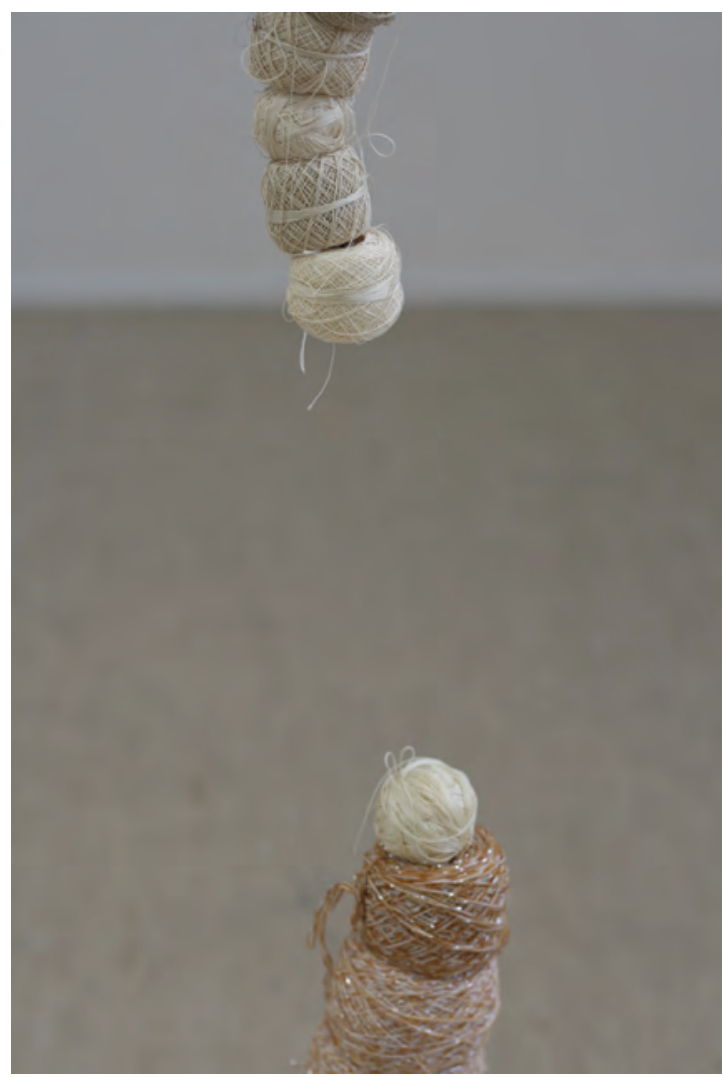

Figure 1. Mae Finlayson, All my love, Anon. (soft beads), (detail), 2013, yarn, dimensions variable

Photo: Mae Finlayson 


\section{Monumental loss}

What speaks from the space of loss? How can other voices enter here?

In taking up craft materials that have already been worked by another maker, the space between making and remaking seems loaded, heavy with possible narrative and meanings. That space - a gap, surely - is also a provocation to imagine what might have been there. I suggest that there are two positions at stake here: firstly, that in deliberately gathering unfinished craft objects, rather than simply starting with new materials, Finlayson and other practitioners engaging with unfinished objects acknowledge that these things have a particular power from their previous accretion of meaning. The implications of this position are discussed further below. Secondly, that in remaking, the actions are a dialogue, a collaboration that is always fraught with loss - two makers, one of whom must always be marked by absence and possibly failure.

The absence of the initial maker is part of a wider series of concerns in the value and status of craftwork, such as is being discussed here. Illustrating the disconnection between a named maker and their work, Grayson Perry's introduction to his exhibition, The tomb of the unknown craftsmen (British Museum, 2011), states that 'the central idea behind my exhibition was about celebrating ego-less creativity' (quoted in Klein 2013: 265). While Perry points to the role of anonymity as, at some level, laudable and enabling freedom, the 'named' status of the exhibition itself sits as an ironic contrast to his claim. Other art projects that engage with unfinished craft objects place negotiation of naming of original makers and their stories at the heart of their work. Rachael Matthews' 2009 exhibition UFO (UnFinished object) project administration service, part of the Jerwood Contemporary Makers 2009 show, and its accompanying blog (2009-2011), documented unfinished knitted works and asked for volunteers to complete them. Each item was accompanied by a narrative, sometimes brief and plausible and, at other times, an elaborate fantasy that speculated about the object's origins, intentions and reasons for failure. Original stories and the original maker are evoked here as a projection, a space not bound by truth, but like Perry's celebration, part of the liberation of these objects into new forms.

In contrast, Hazel Connors' and Felicity Clarke's The unfinishable (2012) takes a more stable approach to connecting unfinished textile pieces with their original makers. Connors and Clarke invited submission of unfinished pieces that 'somehow you can't discard or rework' and '[o]n reflection, there are reasons why it has come to a halt and can't be completed'. Submission of works includes both the piece and a questionnaire (2012). While the final form of the textile work, a circus tent-like 'Extravaganza' made from submitted pieces, did not overtly gesture towards the original makers, accompanying works did. A film piece and book matched objects with their stories, while badges for contributors to wear and ongoing documentations of original makers revisiting their pieces on the project blog accumulated to emphasise an ongoing connection with the makers. The stories accompanying the pieces often emphasised loss and 
memory, and the transmutation of the unfinished works into the shared space of the Extravaganza became an act of catharsis. For Clarke and Connors, the repurposing of these objects required a witnessing of the stories of loss that leave these objects hanging in the world.

The intervention of a second maker into the absence created by the unfinished object, therefore, requires the second maker not only to take a stance on how they will engage with the object's prior existence and the narratives embodied within it, but also to find a mode of intervention. Is the role of intervention to complete the work on its own terms, to attain some state of wholeness, however bizarre or illusory that might be, or to re-imagine the object while refusing closure? The concept of nostalgia, originally a manifestation of homesickness as disease among seventeenth-century Swiss mercenaries (Boym 2007: 7-8), starts with absence: nostalgia is a doubled absence of a person from their place, a void present for both the place and the person. Nostalgia is spatial dislocation as embodied condition.

\section{Tracing hands}

Talking to Janis made me think of him being small and his mother and craft. It made me think of me being small and my mother and craft. When I was growing up my mum was always reinventing her creative self. She was a stained-glass artist, a knitter, a dressmaker, a hairdresser, a ceramicist. The new classes and equipment and materials were always bought and used with initial manic enthusiasm and a sense of forced happiness. Like this is what she'd been looking for, this was it, this would make her complete. Every new project was a squeaky clean new beginning. But ultimately, like many of the projects, she remained incomplete.

I produced a series of works for an exhibition called All my love, Anon. The name of the show was inspired by the letters and sentiments that I unearthed in some of the second-hand gatherings I had hoarded, and also a thank you to the 'accidental donors' of unwanted craft paraphernalia I had repurposed.

I looked at cones of yarn as visually charged objects in their own right and used them as armature, exposed in parts so the colours and rhythmic crisscrossing of the wound lines could be seen. I stretched doilies over the cones like skins held taut in place by dressmaker's pins, sometimes silver, sometimes gold. The pins pull and cluster and define the edges. They pierce the tiny empty spaces of each delicate outer stitch to trace and visually emphasise the "path of the hand' outlined shape. The outlined shapes are irregular and imperfect because the hand-looped stitches are irregular and imperfect. Imperfect perfection. The repetitive actions of the human hand are irregular and imperfect. 


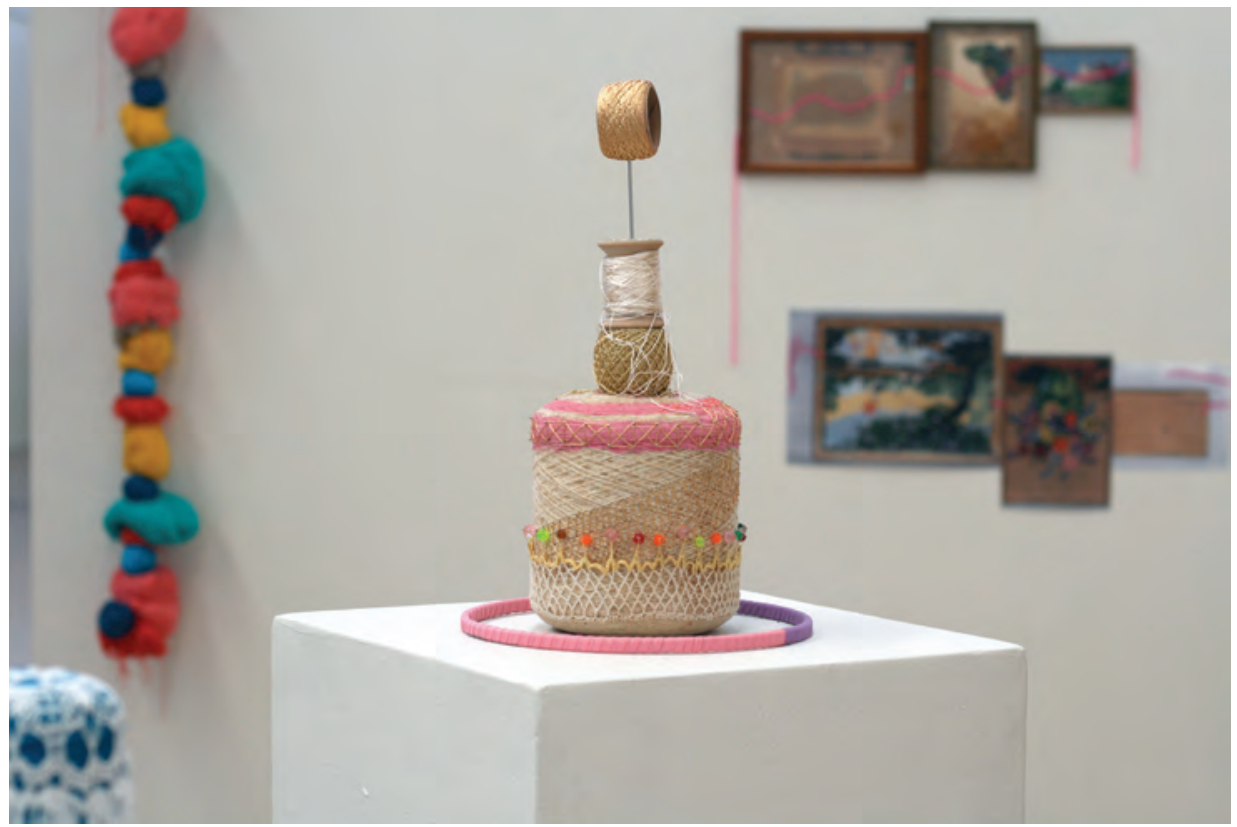

Figure 2. Mae Finlayson, All my love, Anon., 2013, installation view

Photo: Mae Finlayson

\section{Hands and traces}

The palimpsest traces of making in the works shown (Figures $2 \& 3$ ) stand in for the embodied action of the makers, asserting their tangible presence at different times. The materials themselves hold cumulative imprints that show that retracing and remaking is not about overwriting, but instead forms a material dialogue. Constructed through repetitive action, the traces of the hand, and thus traces of the makers, operate as 'signature', inescapably impressing corporeal presence into material form. These traces thus disavow absence, for some part of the maker always remains.

The idea of the signature stands at a remove from the subject. Elizabeth Grosz, drawing on Jacques Derrida, notes that '[t]he signature, as pre-eminently forgeable, transformable, iterable, recontextualizable, provides no guarantee of authenticity, no residue of the full presence of the subject's politics' (1995: 13). In this sense, the signature is constituted by the text - by the object - not imprinted upon it. Lee Mingwei's The mending project (2009) threads the signature into a pre-existing object. Mingwei has commented that '[u]nlike a tailor, who will try to hide the fact that the fabric was once damaged, my mending was done with the idea of celebrating the repair, as if to say, "something good was done here, a gift was given, this fabric is even better than before"' (2013). Mingwei's work asserts the artist's intervention as an inescapable reminder, framed as a utopian 
and redemptive act. Yet this claim for improvement and celebration relies on the retention of Mingwei's ideals, a memory not guaranteed in the material work itself. To the extent that the connection between artist and mended work can be severed or forgotten, the signature here remains an unstable signifier, a fragile attempt at completion.

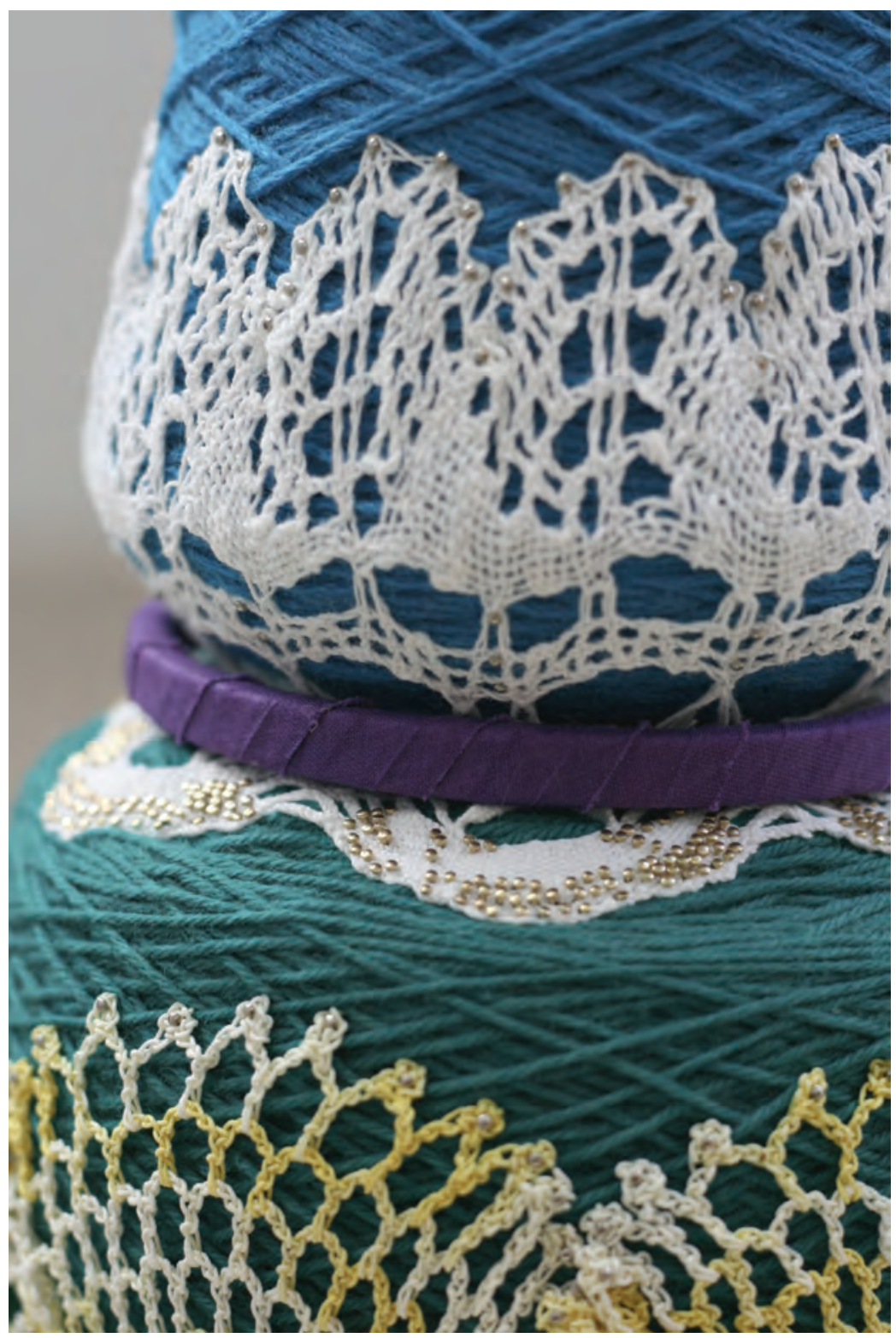

Figure 3. Mae Finlayson, All my love, Anon. (stretched doily) (detail), 2013, yarn, pins and embroidery hoop, dimensions variable

Photo: Mae Finlayson 
Grosz also notes that the signature is not self-contained - it demands a witness, a countersignature (1995: 13-14). The act of witnessing, in the case of Finlayson's and other artists' repurposing of unfinished objects, is not passive, but an active intervention that directly enters a countersignature into the space of the object. In doing so, this action creates recognition that 'as a product the text is an effect of labor, a work on and with signs' (Grosz 1995: 20) and that this labour is tied to the corporeality of the labouring body. The responses to the unfinished works are not purely visual, but tactile. The signature within the works invites sensorial immersion. The tracing action of hands over hands goes beyond mechanical repetition to become an act of profound intersubjective empathy. For Sera Waters, such repetitive crafting 'speak[s] of the physical proximation between art and body, including endurance [and] intimacy' (2012).

The recognition of labour in the unfinished craft projects discussed here is not about economic value, but prioritises a different range of human experiences and expressions. Waters argues that the labour of highly repetitive and therefore physically demanding craftworks should be seen not in 'their economic guises, but hold[ing] value in terms of the output of human energy ...' (2012). To recognise this output of human energy is to insert a different system of value, which places symbolic actions above productivity as judged by the marketplace or the celebrity status of the artists. By reactivating the suspended energy in found and unfinished craft artefacts, the artists valorise the already accumulated repetitive gestures. The revivification of the unfinished object forms a tribute that also attests to the labour of the second maker.

The labour of crafting, and particularly of reworking, takes a specific material form and cannot be divorced from the medium. Ian Farr argues, with reference to Rosalind Krauss, that art practice supported by and aware of the specificity of its medium takes a stance against forgetting through the assertion of materialised memory. The 'remembering' of the medium, therefore, is a 'recursive process' that 'involves invoking the procedure itself' (2012: 15). In this context, materiality is far more than just a set of objects, but a series of rules, devices and constraints that, in unfinished works, we can see being negotiated between the original and subsequent makers.

To insist upon the materiality of the unfinished object also invokes an objectcentred temporality that exceeds human time. Discarded craftworks may be profoundly humanised objects, constructed and invested with human labour, but they continue on after having been discarded. The troubling status of the unfinished object exists both in its incompleteness and its physical persistence. In the face of this unsettling presence, discarding the unfinished object, either in response to an invitation from practitioners or through the mundane strategies of putting it in the rubbish or donating it to an op shop, can function as an expulsion or even exorcism. The removal of the object, a tangible reminder of failure, can be an act of liberation. The afterlife of these unfinished objects in spaces like op shops and markets points to their liminal status as neither easily recognisable commodities nor complete artworks. They remain in stasis, waiting for activation. Michaela Giebelhausen (2006) argues that human intervention is 
required to take objects from speaking in 'murmur[s] of the lost worlds they were once part of' and to frame them as 'audible documents'. This framing is not the authoritative stamp of a single true meaning, but can be 'impeded, reflexive, fragmented, a both/and of complexity and contradiction'. The object, persistent and persisting, stands as witness, requiring interpretation to be brought into human time.

\section{Back of my car}

I am continually hunting and gathering other people's 'little failures' - I compulsively buy up the 'small wrongs' to make right - I want to join together the separated and somehow stem the loss.

There are stories of loss and nonfulfillment 'literally' and metaphorically hidden within my gatherings. I have a collection of 'self improvement' books and magazines - instructional guides on the activities that can distract us from real life. On the inside of a 'how to play great tennis' publication, a hand-scribed message reads 'To my Darling - perhaps this can improve the relationship'. What an odd place for such a heartfelt cry for help. There is comfort in the thought that, if we just follow the directions correctly, everything will work out.

I have been collecting discarded textile craft materials for years and years. After 15 years of living in London I shipped a full container back to Australia. At first, while studying, it was a cheap way of making artwork. But when I began to think about why I chose certain items over others, why I set certain rules for my selections and their end use, I knew it was becoming more than simply a means to an end. In terms of 'rules', I will sometimes buy a bag of half-used rolls of wool that have been put together in the sorting space of an op shop. They may have been inadvertently curated into their clear plastic by a volunteer according to their colour or gauge - I will limit myself to only using those wools for a work - using someone else's aesthetic choices, however random or unintended they may be. But I might just as easily change the rules, and leave the wools sealed in their soft display casing to stand alone as a found assemblage, or add it to others to become part of a bigger whole. Through this process I am making these objects my own by making decisions on what to take while, at the same time, playing with limits of decision-making by using the decisions of others as my starting points.

My car is both a vessel and a vessel. One for travelling in to take me to the garage sales, the op shops and the flea markets; and one for holding and containing the contents of my acquisitions. I am absorbing the thrown out, forsaken craft projects of others to build my own never-ending craft project. 
craft + design enquiry

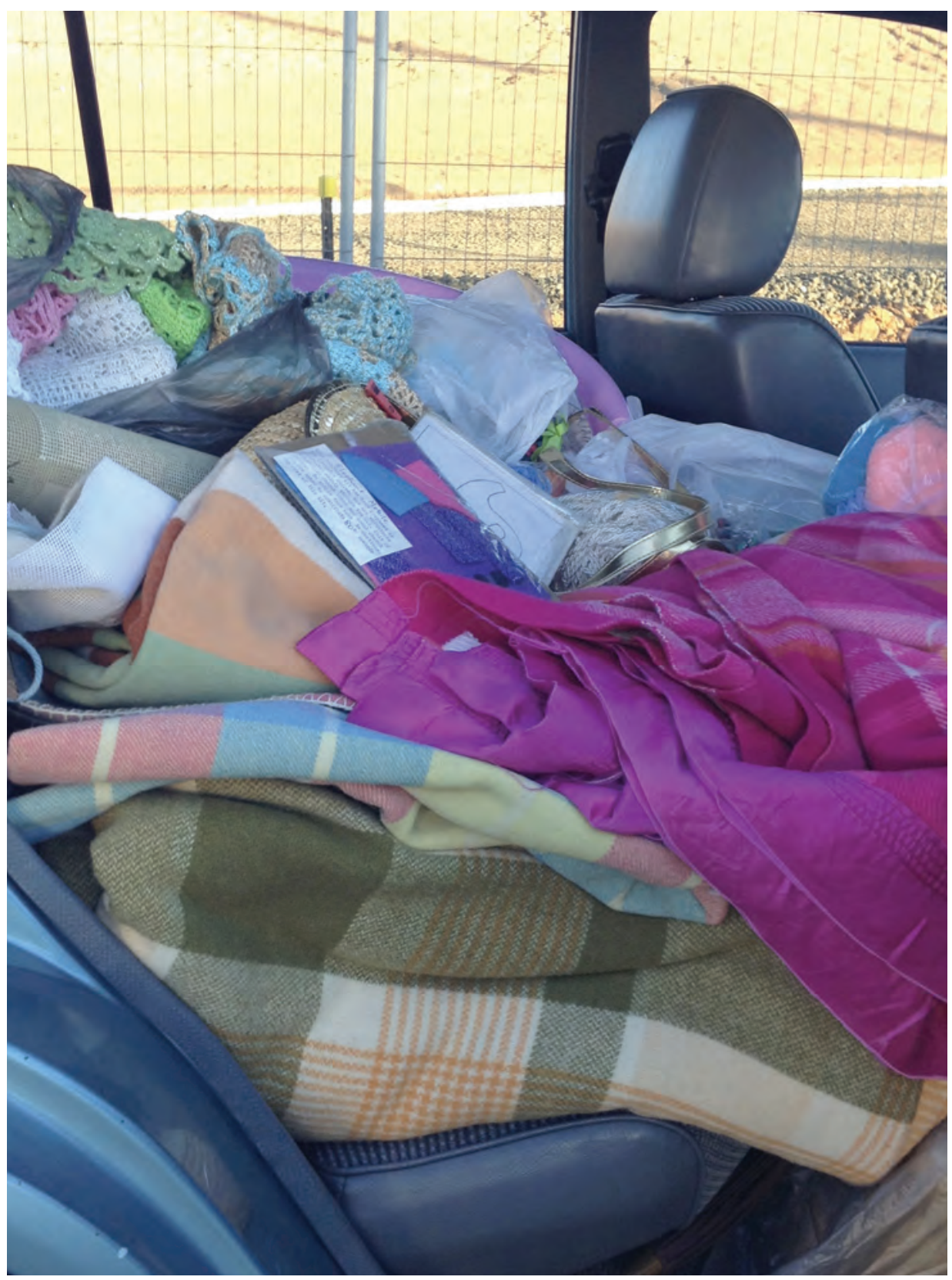

Figure 4. Mae Finlayson, Back of my car, 2013, digital image Photo: Mae Finlayson 


\section{Back to the future}

The curatorial perspective - of collection, categorisation, and selection of objects - emphasises the agency of the person, but really, thinking about the looming pile on the back seat, does this seem an assertion of control in the face of threat? For Finlayson, gathering and holding these objects before reuse is another investment of time and labour and a continual negotiation with the physical presence of these objects as a burden to be carried. In this sense, the presence of the human is always in correspondence with the agency of the nonhuman object of the non-human. Jane Bennett asserts the 'radical kinship of people and things' (Bennett 2005: 463) formed through assemblages, in which both people and things are present as actants within a network. The agency of one element in the network does not compromise the agency of another.

The significance of this back seat assemblage lies also in its status as a personal collection rather than an institutional one. While Finlayson employs a curatorial aesthetic, in the form of rules and boundaries for exclusion and inclusion, she is not bound by ethics of conservation or directives of inclusiveness and universality. Beyond a need to hold and preserve, this collection forms a reservoir of possibilities, where the dialogue between objects acts as an expressive mode. An open-ended approach to assemblages is liberating, allowing the objects to combine and recombine, to speak and be silent, and to hold agency alongside the makers. The 'ego-less creativity' can here encompass makers and objects, placing all these elements in a dialogue in which the necessary asynchronicity of the makers is bridged by the temporal continuity of objects.

The revivification of unfinished objects, which resists a linear chronology, suggests reflective nostalgia as a conceptual frame. Using materials inscribed by the past does not require that their subsequent use match or mirror their origins. Boym (2001) identifies a typology of two forms of nostalgia, restorative and reflective. While restorative nostalgia tries to reconstruct and therefore return to the lost home, reflective nostalgia 'thrives on algia (the longing itself) and delays the homecoming - wistfully, ironically, desperately' (Boym 2007: 13). Finlayson's repurposing of unfinished craft objects does not seek a reconstruction, but instead acknowledges the impossibility of resolution, taking it into the realm of reflective nostalgia. Boym argues that reflective nostalgia 'reveals that longing and critical thinking are not opposed to one another, as affective memories do not absolve one from compassion, judgement, or critical reflection' (2007: 15) Grappling with loss and absence, reflective nostalgia holds this space by refusing to retreat into a fantasy of restoration. Instead, reflective nostalgia opens onto a future that is undetermined, but not isolated from the past. The revivification of unfinished objects does not have to replicate the past, but can borrow from it.

Reflective nostalgia, which eludes both teleological progress and the lure of a golden age, is a productive explanation for the lure of unfinished craft objects as materials for creative repurposing. The work of re-imagining these objects 
also calls us to consider the modes through which reflective nostalgia might work. The tangible traces of labour in the objects, carried out by original and subsequent makers, point to the vital nature of process. We suggest that these objects point towards understanding reflective nostalgia as constantly coming into being, a continual reimagining and reinvention that cannot ever be finished.

\section{Conclusion}

Unfinished craft objects pose a series of problems and potentials: their tangible presence asserts their agency as objects, while they simultaneously gesture to the interrupted labour of their construction and their disconnection from their original maker. As the starting point for a process of revivification, unfinished objects are imprinted in an asynchronous dialogue where the subsequent maker must consciously address choices of selection, assemblage and intervention. In returning to these objects, subsequent makers open a space to speak of loss, absence and nostalgia.

If nostalgia is the product of dislocation, its expression in the form of craftwork is a potent remaking of that dislocation. Craft, with its embedded and embodied tradition - the choice of techniques, patterns, materials - can be a way of replicating and thus remaking the past, of summoning it one stich at a time into the present. In considering the links between craft, making stitch and nostalgia, we emphasise that memory is active. If memory, framed by nostalgia, is not a site, space, or hallowed and frozen object, but an open-ended process, it can enable affective and playful dialogue between makers in the repurposing of objects. The absence within the unfinished object invites its revivification into an afterlife, carrying the past into the future.

Mae Finlayson is a practising artist living in Launceston, Tasmania. Her individual work explores the handmade and familiar, while her collaborative work with Team Textiles creates audience-activated artworks. She trained at Goldsmiths College, University of London, and Royal College of Art, London. She currently lectures in visual art at the University of Tasmania and is chair of Sawtooth ARI.

Dr Karen Hall is a lecturer in Theory at the Tasmania College of the Arts, University of Tasmania. Her research interests revolve around the reimagining of the past from the present with themes including medievalism and lost race stories in science fiction.

\section{References}

Bennett, J. 2005, 'The agency of assemblages and the North American blackout', Public Culture, vol. 17, no. 3, pp. 445-66.

Boym, S. 2001, The Future of Nostalgia, New York: Basic Books. 
- - 2007, 'Nostalgia and its discontents', The Hedgehog Review, vol. 9, no. 2, pp. 7-18.

Connors, H. \& Clarke, F. 2012, The Unfinishable: A (Great) Stitch Reclamation Project, viewed 3 June 2013, http://theunfinishable.com/index.html.

- - 2012-2013, The Unfinishable, blog, viewed 3 June 2013, http:// unfinishableblog.blogspot.com.

Farr, I. 2012, 'Introduction: Not quite now I remember it', in lan Farr (ed.), Memory, London: Whitechapel Gallery and Cambridge, Massachusetts: MIT Press, pp. 12-27.

Giebelhausen, M. 2006, 'Lost worlds: How the museum remembers', Working Papers in Art and Design, no. 4, viewed 16 May 2013, http://sitem.herts. ac.uk/artdes_research/papers/wpades/vol4/mgfull.htm.

Grosz, E. 1995, Space, Time and Perversion: The Politics of Bodies, St Leonards, NSW: Allen \& Unwin.

Klein, J. 2013, Grayson Perry, London: Thames \& Hudson.

Matthews, R. 2009-2011, UFO (Unfinished Object) Project Administration Service, blog, viewed 3 June 2013, http://ufoadministration.blogspot.com.

Mingwei, L. 2013, 'Projects', viewed 4 June 2013, http://www.leemingwei.com/ projects.php.

Waters, S. 2012, 'Repetitive crafting: The shared aesthetic of time in Australian contemporary art', craft + design enquiry, no. 4, viewed 26 February 2013, http://epress.anu.edu.au?p=202481. 
This text taken from craft + design enquiry issue 6, 2014, Craft.Material. Memory, Edited by Anne Brennan and Patsy Hely, published 2014 by ANU Press, The Australian National University,

Canberra, Australia. 